\title{
Formation of a Model for Tracking and Supporting the Development of an Enterprise Management System
}

\author{
Fedor P. Zotov \\ Ural State University of Economics \\ Yekaterinburg, Russia \\ fzotov@inbox.ru
}

\begin{abstract}
In this work, we conducted a study in the field of functioning and development of enterprise management systems. The objective of the study was to form methods and means, the use of which contributes to the development of the enterprise management system. The study used the provisions of the system approach, the concept of systems thinking, and the general theory of systems. The enterprise management system was considered as a complex, open, and self-organizing socioeconomic system. The key interconnected subsystems and system elements, combined with the principles of management improvement, have been studied. The analogues and prototype of the concepts and models of management systems with reference to the area the area have been described. The impact of environmental factors and forces of influence has been considered as the initial motives for the development of the management system. As a result of the work, a conceptual model to track and support the development of the enterprise management system, its individual subsystems and functions, aimed at transforming the management system, mastering new methods in management practice, has been created.
\end{abstract}

Keywords-enterprise; system approach; systems thinking; management system; system functioning and development; model for tracking and supporting; expected economic result.

\section{INTRODUCTION}

According to the economic competitiveness rating of the Institute of Management Development (IMD), the management of Russian enterprises has been ranked in the $5^{\text {th }}$ decade of the top countries and economies in terms of "management practices" from the group of "business efficiency" factors for a long time. From the position of the creators of the rating (which includes M. Porter), low places in the rating indicate the inability of the enterprise's management to create and maintain a business environment sufficient to conduct competitive activities.

This problem is also evidenced by the data of Rosstat, according to which the proportion of industrial enterprises in the Russian Federation that solve managerial problems through organizational innovations has not exceeded $3-5 \%$ for a long time.
Due to this passivity of management, the country's international authority is weakened, market opportunities are lost, and the competitiveness of Russian enterprises is reduced.

In relation to this problem, the author puts forward a number of hypotheses, namely:

- the development of an enterprise management system is a way to overcome the innovative passivity of management

- the lack of methodology for tracking and supporting of management system development is one of the reasons for the innovative passivity of enterprise management;

- the application of management practices for enterprise management are necessary but insufficient means for the development of the enterprise management system;

- tracking and supporting for the application of management practices is a sufficient means for the development of the enterprise management system.

The following discussion presents an attempt to resolve the accepted hypotheses. The following sequence of actions is defined as the initial conditions for setting the research task: to simulate the current state of the enterprise management system; to simulate conditions conducive to the application of management practices, concepts, and models on the part of the enterprise management; to simulate the focus of management actions on the development of the enterprise management system; to achieve the expected result by modeling successive states of the system.

\section{LITERATURE REVIEW}

In the study, the conceptual base of systems thinking and the system approach, the concepts and patterns of the general theory of systems have been updated. In order to solve the research problem, it was important to study the theoretical developments described in the fundamental works of management classics (Warner M., 2001). L. von Bertalanffy, one of the founders of the concept of systems thinking and the general theory of systems, testified in his writings that every organization is, first of all, "a set of objects that are in a stable 
interaction with each other and the environment" (Bertalanffy L. von, 1968). According to K. Boulding, knowledge of the nature of the parts of an organizational system, the interactions between parts, and the relationship between a system and its environment is important for applying scientific models of a system approach to managing an object (Boulding, 1956). The S. Beer's model of a viable system shows how cybernetic laws shape the behavior of all complex systems (Beer, 1979). J. Forrester believed that a feedback information theory could be applicable in a system approach, which would reveal the secrets of complex systems, with multiple feedback loops, and non-linear systems to which social systems are assigned (Forrester, 1971). Corrective actions were considered by J. Forrester as components of the "feedback loop". The applicability of the systems approach in management was redefined after P. Checkland had created the "soft systems" methodology (Checkland, 1989). According to P. Checkland, real-world problems can be formulated by describing 2 system states, current $\mathrm{S} 1$ and expected S0, and choosing alternative reduction options (S0-S1). P. Senge attributed "systems thinking" to one of the 5 system technologies (subjects), the totality of which is designed to implement the concept of "learning organization" (Senge, 1990). According to P. Senge, a system approach considers the enterprise as a whole and helps to understand the nature of inherent interconnections and relationships with the external environment. R. Ackoff's designs took shape in a category called the "circular organization", which in fact is a kind of democratic hierarchy. According to R. Ackoff, an organization is a form that seeks to encourage the active contribution of its employees (Ackoff \& Gharajedaghi, 1996). One of the outstanding management practitioners of T. Ohno applied the concept of systems thinking to the organization of production, which was implemented in the form of a production system, which allowed ensuring the rhythm of production and limit the use of inventories (Ohno, 1988). T. Peters created the 7S model, which proposed the following system elements: structure, strategy, systems, abilities, employees, management style, and shared values (Peters \& Waterman, 1982). According to T. Peters, the difference between companies with an improved management system is the ability of management to cope with uncertainties when influencing a problem situation. According to the philosophy of P. Drucker, all management institutions exist to achieve certain goals. The purpose of the industrial enterprise management system is to ensure the creation of public goods in the most productive way (Drucker, 1973). J. Thompson considered overcoming uncertainty as the primary function of administration. According to J. Thompson, an organization's ability to deal with uncertainty "is the essence of the administrative process" (Thompson, 1967).

Among modern researchers, one can also note many adherents of the concept of systems thinking and a system approach. Much attention is paid to the influence of uncertainties in the development of an enterprise management system. A number of Russian researchers analyzed the specifics of the formation and development of "cumulative" risk management systems (Khachaturyan, Koryagina \& Nikishova, 2018). It is shown that the special importance among all types of risks of the business owner is associated with the risk of a decrease in his business activity. In this regard, a proprietary risk management system was proposed as a part of the process management. R. Edgeman's research focuses on creating an operational excellence model based on complex management systems that include elements external to the enterprise management system, such as various stakeholders, intermediary forces, corporate culture, and representative corporate processes (Edgeman, 2018). The goal of the study of D. Skoumpopoulou, T. Waring was to bridge the gap regarding how the management system can influence or contribute to cultural change at a major British university (Skoumpopoulou \& Waring, 2017).

V. Singh and P.M. Singru proposed new management methods and tools related to the graph theory methodology to study the impact of various lean initiatives in relation to the enterprise management system (Singh \& Singru, 2018). They used a physical interpretation of existing quantitative methods, namely the types of dissimilarity coefficients. The possibilities of new management practices to reduce uncertainty in the development of an enterprise management system have been shown.

A group of authors (V.P. Khorolskyi, L.P. Rybalko, and others) created methodological support for the management of restructuring of production systems in relation to the production of steel mills in the face of uncertainty (Khorolskyi, Rybalko \& Khorolska, 2016). They investigated the optimization of demand for steel products in European countries using a balanced scorecard. Based on this methodology, minimization of operating costs and maximization of the economic result have been shown. A relation to increase the competitiveness of products, taking into account the use of the main provisions of a number of international standards for quality management and supply chain security was found. It is proved that the restructuring of the production processes of enrichment and the operational flow of concentrate has increased the balance sheet value of mining and metallurgical enterprises to the level of requirements for metallurgical production in the European Union.

A team of authors (A. Melander, M. Lofving, and others) investigated the classical methodology by Hoshin Kanri. On its basis, methods for managing the production of small and medium enterprises have been proposed (Melander et al.). This work presents the results of implementing a project based on Hoshin Kanri for four small enterprises that brought together teams of trainers and researchers to work together at the project implementation stage.

\section{MeTHODS AND MATERIALS}

Management classics have recognized that adherence to the concept of systems thinking and a system approach is the most ordered basis for the formation of management of complex areas of interconnected activity. In this study, the following key principles of consistency have been adopted: the relationship of the whole and the parts; the primacy of the whole over the parts; the interaction of any object with many others; the presence of a holistic external environment and its impact on the system; dynamism of the structure and 
characteristics of elements; the uncertainty and unpredictability of the behavior of the system and its external environment; sustainability and/or effective adaptation (Sadovsky, 1989). When modeling, it was taken into account that systems are characterized by system-wide regularities, such as: integrity (emergence, additivity, integrativity); orderliness (communicativeness, hierarchy); feasibility (equifinality, potential effectiveness); development (historicity, self-organization).

In the selection of system concepts and provisions, both the classical achievements of the management guru and modern evidence of the increment of new knowledge in this field were used. The definition of the system as "a complex of interconnected elements forming certain integrity, or as a set of objects that are in stable interaction with each other and the environment" has been accepted (Bertalanffy L. von, 1968). An integral part of the system is the relationship between its elements, which ensure the emergence and preservation of integrity. When modeling, the concept of feedback is used, this is the basis of self-organization of systems. The structure of the system, which stabilizes its existence and basic properties, is based on the connections between the elements. In order to emphasize the dynamics in this study, we used categories such as the state of the system that characterizes the functioning, the temporal "cut" of the system, and the behavior of the system that characterizes the development of the system, the transition of the system from one state to another. According to the classification of Ju.A. Shreider, the enterprise management system under study is assigned to socioeconomic, complex, large, real, focused, and valueoriented systems (Shreider, 1989). The most significant for socioeconomic systems is their classification by degree of organization. Under this classification, the enterprise management system is presented in the form of a selforganizing system. Guided by the $80 / 20$ rule, the study selected $20 \%$ of system elements, which $80 \%$ determine the functioning and development of the system. System elements have been selected for the task of forming a model established in the study on the transition of the enterprise management system from the current state, characterized by an unsatisfactory economic result, to a state. It is proposed to use the achievement of the expected economic result as the goal of the study. In solving the problem, it was customary to use methods of expert evaluations due to the fact that the problem was solved under the high initial uncertainty.

Translation of a verbal description of the situation into a formal one, comprehension, interpretation of the results obtained have become an integral part of almost every stage of modeling the behavior of a self-organizing system. According to the modern understanding of the system approach to solving research problems, intangible system elements (organizational culture, enterprise reputation), as well as the scope, boundaries, interests of stakeholders, environmental resources (labor, energy, finance, knowledge, etc.) are taken into account.

\section{RESULTS AND DISCUSSIONS}

The task of forming methods and means, the application of which contributes to the development of the enterprise management system, was solved based on the key provisions of the system approach and the general theory of systems, both in classical and in modern concepts. In particular, the provisions of P. Chekland's "soft systems" methodology were taken into account, among others, the description of the current S1 and expected S0 states of the management system in the following interpretation (Chekland, 1989):

- identifies the economic result on the object of the enterprise management system in the current state, which is analyzed from the perspective of influence forces and environmental factors, $\mathrm{S} 1$;

- the economic result is estimated at the facility of the enterprise management system for the expected state, S0;

- the method of measuring the economic result, S0, S1;

- the management of the enterprise makes a decision on the application of influence means on the system in the form of management methods to achieve the expected economic result, $\mathrm{S} 0$;

- $\quad$ in case of insufficient effectiveness of the application of management practices, a decision is made to continue influencing the system in the form of applying support and support methods to achieve the expected economic result.

The indicated conditions are shown in Figure 1.

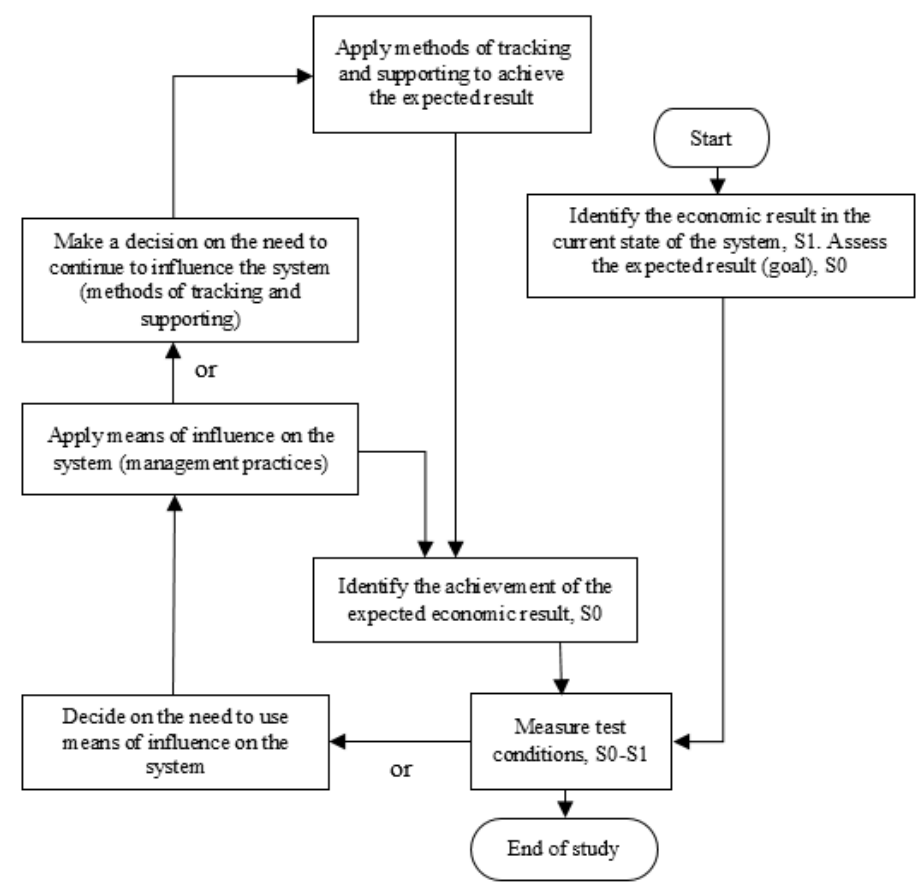

Fig. 1. The statement of the problem on the formation of methods and means, the use of which contributes to the development of the enterprise management system

As analogues solving this problem, a number of theoretical concepts and models, known as cause-effect or process models, the purpose of which is to build a set of managerial processes, have been studied. In the content of such models, it was important to find a set of actions that directly (management practices) or indirectly (tracking and supporting 
methods)) allow you to influence the objects of the control system and expect to get a new economic result.

In this regard, it seemed to the author to consider the most suitable procedural model proposed by T. Kono and known as the 5-level star (Kono, 1984). T. Kono's model allows, through successive iterations, consisting of 7 steps, to approach the expected result of the business strategy of the enterprise. The initial step in approaching the result is to analyze the current state of affairs at the enterprise (step 1). If the results of the analysis are considered to be unsatisfactory or there is a tendency to worsen the situation, then there is a basis for influencing the current state (step 2). First of all, it affects the management of the enterprise - the subject of the management system. Management is expected to review the business strategy of the enterprise. The decisions on production technology, on the range of products, as well as sales markets and distribution channels are reviewed (step 3). Further, the state of potentials is checked to implement the new strategy: innovative (step 4), production (step 5), and sales (step 6). If the potentials are found promising, it is expected that the product will be delivered to the market at the best cost-quality ratio (step 7), which, by design, should change the current state of affairs at the enterprise (step 1).

The concept of the "value chain" by M. Porter, that is, the sequence of activities that increase the value of the expected result of the enterprise's activity (Porter, 1990), is considered as the second analogue. These activities include those related to the production and delivery of products to the consumer. Ancillary activities contribute to a direct increase in value or allow you to act more efficiently. In the model of the "value chain" by M. Porter, it is shown that all types of activity are connected with each other and form a system of processes. In order to successfully respond to external influences and ensure the achievement of goals, it is important to seek to improve the process system. The "value chain" model allows you to analyze the methods and means of achieving long-term competitiveness of the enterprise.

As a third analogue, the model of functioning of the enterprise management system developed by S. Beer has been adopted. In S. Beer's model, 5 subsystems of the enterprise management system have been distinguished, each of which performs a specific function. The model allows you to identify the necessary structures, information, and processes for each level of the enterprise management (Beer, 1979). The first subsystem includes units performing regulatory functions (control of work processes, stocks, resources, etc.). The second subsystem consists of bodies coordinating the relations of units, weakening fluctuations and conflicts between systems (departments of regulation, quality, standardization, labor protection). The units of the third subsystem form the management bodies of the units ("vertical command axis"). They contribute to the stabilization of the internal environment, support the emergence and synergy in the actions of the first and second subsystems. The units of the fourth subsystem analyze the state of the external and internal environment of the enterprise. The divisions of the fourth subsystem are the "intellect" of the enterprise and prepare analytics for the top management of the enterprise about the current state of affairs at the enterprise (Advanced Planning
Department, Analytical Department, Corporate Planning Department, etc.). The fifth subsystem includes the top management of the enterprise. It forms an organizational culture, policy, controls the balance of actions of the third and fourth subsystems.

As a prototype, in this study, the model of the functioning and development of S. Demchenko's management system, which is built, on the one hand, by summarizing these analogues, and, on the other hand, it focuses on obtaining the expected economic result in the context of Russian realities, has been considered (Demchenko, 2010). The model is composed of 11 blocks. As in the T. Kono model, a block for analyzing the current economic result (block 5) has been introduced. A comparison of the current indicators of the management system functioning, that measure the economic result (sales dynamics, profitability, market share, etc.) with the target settings (blocks 2 and 6) has been made. Target settings and performance indicators are set by influence forces (block 1), taking into account the state of the external and internal environment of the enterprise. They are periodically reviewed, depending on the current economic result and under the influence of the industrial culture of the enterprise (block 11). The forces of influence (block 1) refer to all the parties that predetermine the very existence of the enterprise. According to the author of this model, they include founders and influential shareholders who decide on the feasibility of the existence of the enterprise; government bodies that set the parameters for doing business, administrative and tax regulation, deductions for social needs, the minimum level of wages; top management; consumers of products and suppliers of raw produce, materials, and components; wage-earners. The model takes into account the interests of all participants at all stages of the enterprise (block 7). The model includes an analysis of the competitive product availability in the enterprise that deserves the attention of consumers and exceeds the products of competitors (blocks 3 and 9). If the analysis shows that the economic result is unsatisfactory, the production potential (block 8) and the sales potential (block 10) of the enterprise are checked. One of the decisive conditions for the enterprise to achieve the expected result is the commitment of its management to the development of the enterprise management system (block 11).

Summarizing the described analogues, it seems important to conclude that in each of them, there are structural elements and actions that are suitable for studying the behavior of enterprise management systems and each of them should be recognized as a significant contribution to the general theory of systems. It is important to note that in the described analogues:

- the focus on the expected economic result is not clearly expressed;

- means of tracking and supporting for achieving the expected result (goal), which allows mechanical transfer of the model during its implementation, are not included;

- the principles of management improvement used as basic research criteria are not reflected; 
Each principle is found to be compatible with an element

- the behavior of the elements (objects) of the management systems subjected to research is not consistent with the principles of improving management.

Based on the considered developments, a conceptual model of tracking and supporting for the development of the enterprise management system has been formed in this study.

In the author's model:

- the research area of the enterprise management system has been identified by highlighting the key elements of the system;

- the principles of improving management have been agreed upon with the elements of the management system allocated for research;

- the point application of management practices in the management system has been defined;

- the point application of tracking and supporting methods for achieving the expected economic result has been determined;

- monitoring of the achievement of the expected economic result has been established.

The conceptual model includes elements of an enterprise management system, according to the $20 / 80$ rule, in particular: goals; management staff (subject of the system); executive staff; team communications; knowledge; processes.

The decision of the enterprise management, aimed at overcoming the current economic result, is defined as the initial stage of the model. Such an event is formed under the influence of influence forces and the state of the market environment (stage 0 ).

At stage 1, the principles of improving management are selected, and their interpretation and comments are given to understand the relevance and value of the principles in the development of the system. In modern management, there is no single and universally recognized set of principles for improvement. Almost every classic management researcher presents his/her own set of principles. The principles of improving the management of $\mathrm{H}$. Fayol, H. Emerson, E. Deming, W. Edwards Deming, P. Drucker, D. Scott Sink, T. Peters, R.H. Waterman Jr. are known, from modern examples - the principles of the Toyota production system.

In the author's model in a ratio of $20 / 80$, a number of principles for improving W. Edwards Deming are highlighted, namely:

- commitment by the company management to longterm goals;

- $\quad$ leadership as a method of work;

- the removal of barriers to the work of people;

- $\quad$ team building for the destruction of borders between functional units;

- the enterprise continuous improvement. of the system. The combination of the element with the principle of improving management makes it possible to justify the development of the system and determine the means of influencing the system.

The set of system elements, according to the changes of which it is proposed to monitor the development of the system, is selected at stage 2 . At stages 3, 6, and 9, an analysis of changes in each combined element is carried out.

At stage 5, it is proposed to apply management practices as a means of influencing elements of the system. At stage 8, the model incorporates the mechanism of corrective management actions as a means of tracking and supporting the development of the enterprise management system (Zotov, Astratova \& Butko, 2018).

Observations of management practices at Russian enterprises indicate that activities undertaken by a company management in order to develop a management system, for the most part, remain without an assessment of the economic result. Therefore, at stages 4,7 , and 10 , it is proposed to introduce into the model an assessment of the achievement of the expected economic result in the management system objects and a subsequent assessment of the satisfaction of the forces of influence with this result.

\section{CONCLUSION}

In order to solve the research problem, the theoretical knowledge base of management classics, which reflects the area of functioning and development of management systems in a broad sense, has been updated and the results of the development of modern researchers from the perspective of the concept of systems thinking, the general theory of systems, and the system approach have been considered in the work. The analogues and prototype of the concepts and models of enterprise management systems have been described as applied to the research task. On this basis, the author's conceptual model of tracking and supporting the development of an enterprise management system has been formed.

The inclusion in the structure of the model of principles for improving management, conditions for the compatibility of the principle with the management system element, methods and means of tracking and supporting for the development of the enterprise management system have become distinctive features of the author's model. In each of the states of the management system, an assessment of the economic result is provided. It is proposed to apply the mechanism of corrective management actions as instrumental methods and means of system.

The generated model is intended to promote the development and improvement of the enterprise management system, its individual subsystems and functions, as well as decision-making on transformations in the management system, on the development of new methods in management practice. influencing the subsystems and elements of the management 
[13] Kono T. Strategy and structure of Japanese enterprises. New York: M. E. Sharpe, 1984.

[14] Melander A., Lofving M., Andersson D. et al. Introducing the strategic management system in manufacturing SMEs. Management Decision. 2016. Vol. 54. Issue 10. Pp. 2507-2523.

[1] Ackoff R.L., Gharajedaghi J. Reflections on systems and their models Systems Research and Behavioral Science, Vol. 13. 1996. Pp. 13-22.

[2] Beer S. The Heart of Enterprise. Chichester: Wiley, 1979.

[3] Bertalanffy L. von. General System Theory. Harmondsworth: Penguin, 1968.

[4] Boulding K.E. General systems theory - the skeleton of science. Man Sci. 2. 1956. Pp. 197-208.

[5] Checkland P.B. Soft systems methodology. In Rational Analysis for a Problematic World. J. Rosenhead (ed). Chichester: Wiley. 1989. Pp. 71100.

[6] Demchenko S.G. (2010) Enterprise Management: A Model for Success. Actual Problems of Economics and Law. No. 1. 2010. Pp. 39-46.

[7] Drucker P. Management: Tasks, Responsbilities, Practicies. New York: Harper \& Row, 1973.

[8] Forrester J.W. World Dynamics. Portland. Oregon: Productivity Press, 1971.

[9] Edgeman R. Excellence models as complex management systems: An examination of the Shingo operational excellence model. Business Process Management Journal. Vol. 24. Issue 6. 2018. Pp.1321-1338.

[10] International Encyclopedia of Business and Management. 2nd edition. Warner M. (ed), 2001.

[11] Khachaturyan M. V., Koryagina I. A., Nikishova, M. The aspects of formation and development of possessory risk management systems of organization in the russian economy. Innovation Management and Education Exellence through vision 2020. 2018. Vol. I-XI. Pp. 24-34.

[12] Khorolskyi V.P., Rybalko L.P., Khorolska O.V. Intellectual management system of corporate enterprise with use of the balanced scorecard. Marketing and Management of Innovations. Issue 2. Pp. 188202.
[15] Ohno T., Mito, S. Just-in-Time for Today and Tomorrow. Cambridge. MA: Productivity Press, 1988.

[16] Peters T. J., Waterman R.H. In Search of Excellence: Lessons from America's Best-run Companies. New York: Harper \& Row, 1982.

[17] Porter M. The Competetive Advantage of Nations. Harvard Business Review. 1990. No.2. Pp. 73-93.

[18] Sadovsky V.N. (1979) The Principle of Systemicity, a System Approach, and General Theory of Systems. System Research. Yearbook 1978. M.: Nauka. 1979. Pp. 29-54.

[19] Shreider Ju. A. (1979) Set Theory and Systems Theory. System Studies. Yearbook. 1978. M.: Nauka, 1979. Pp. 70-85.

[20] Senge P. The fifth Discipline: The Art and Practice of the Learning Organization. New York: Doubleday / Currency, 1990.

[21] Singh V., Singru P. M. Graph theoretic structural modeling based new measures of complexity for analysis of lean initiatives. Journal of manufacturing technology management. 2018. Vol. 29. Issue 2. Pp. 329349.

[22] Skoumpopoulou D., Waring T. Cultural change through the implementation of an enterprise system. AUK university case study. Journal of enterprise information management. 2017. Vol.30. Issue 5. Special issue SI. Pp. 809-830.

[23] Thompson J.D. Organizations in action: Social science bases of administrative theory. New York: McGraw-Hill, 1967.

[24] Zotov F.P., Astratova G.V., Butko G.P. Application of the Corrective Managerial Actions Mechanism in Projects Aimed at Improvement of the Enterprise Management System. Lecture Notes in Management Science. 2018 8th ESE International Conference on Sports, Health and Management (ESE-SHM 2018). 2018. Vol.91, Pp. 260 - 265 